\title{
Survival from colorectal cancer in Germany in the early 2 Ist century
}

\section{O Majek 1,2 , A Gondos', L Jansen', K Emrich ${ }^{3}$, B Holleczek ${ }^{4}$, A Katalinic ${ }^{5}$, A Nennecke ${ }^{6}$, A Eberle ${ }^{7}$, H Brenner $^{*, 1}$ and the GEKID Cancer Survival Working Group ${ }^{8}$}

'Division of Clinical Epidemiology and Aging Research, German Cancer Research Center, Im Neuenheimer Feld 58I, D-69I 20, Heidelberg, Germany; ${ }^{2}$ Institute of Biostatistics and Analyses, Masaryk University, Kamenice 126/3, 62500, Brno, Czech Republic; ${ }^{3}$ Cancer Registry of Rhineland-Palatinate, Institute for Medical Biostatistics, Epidemiology and Informatics, University Medical Center, Johannes Gutenberg University Mainz, Obere Zahlbacher Straße 69, D-55 I31, Mainz, Germany; ${ }^{4}$ Saarland Cancer Registry, Präsident-Baltz Strasse 5, D-66119, Saarbrücken, Germany; ${ }^{5}$ Cancer Registry of Schleswig-Holstein, Institute of Cancer Epidemiology, University of Lübeck, Ratzeburger Allee 160, Haus 50, D-23538, Lübeck, Germany; ${ }^{6}$ Hamburg Cancer Registry, Ministry for Health and Consumer Protection, Billstr. 80, 20539, Hamburg, Germany; ${ }^{7}$ Cancer Registry of Bremen, BIPS - Institute for Epidemiology and Prevention Research, Achterstrasse 30, D-28359, Bremen, Germany

BACKGROUND: Colorectal cancer is the most common cancer in Germany and the second most common cause of cancer-related deaths in both men and women. The aim of this study is to provide detailed analysis of recent developments in survival of colorectal cancer patients using newly available data on a national basis.

METHODS: We included data from I I German cancer registries covering a population of 33 million inhabitants. Period analysis and modelled period analysis were used to provide most up-to-date estimates of 5-year relative survival in 2002-2006.

RESULTS: The analysis was based on records of 164996 colorectal cancer patients. Five-year relative survival was $63.0 \%$ overall, decreased with age and was significantly higher among women than among men in patients under 75 years. Overall age-adjusted 5 -year relative survival increased from 60.6 to $65.0 \%$ over the period 2002-2006. Significant increase in survival was only observed in patients with localised or regional disease. Highest subsite-specific survival was observed in patients with cancer in descending (67.7\%) and ascending (66.5\%) colon.

CONCLUSION: Survival of patients with colorectal cancer continued to increase in the early 2 Ist century in Germany, with 5-year relative survival reaching $65 \%$ in 2006 . However, lack of progress still persisted in patients with advanced disease.

British Journal of Cancer (2012) 106, 1875-1880. doi:10.1038/bjc.2012.189 www.bjcancer.com

Published online 3 May 2012

(c) 2012 Cancer Research UK

Keywords: colorectal cancer; survival; period analysis; subsite; morphology

Colorectal cancer is the most common cancer in Germany and the second most common cause of cancer-related deaths in both men and women (Husmann et al, 2010; GEKID, 2011). This underlines the need for effective colorectal cancer control. Analysis of population-based survival of cancer patients provides an invaluable tool for measuring progress in these activities.

Until recently, analyses of population survival in Germany were based predominantly on data from the Saarland registry covering only $1.3 \%$ of the total population ( 1.0 million inhabitants). This registry provided data for the international EUROCARE (Brenner et al, 2009a), EUNICE (Gondos et al, 2008) and CONCORD (Coleman et al, 2008) studies. Since the 1990s, population-based cancer registries have been built up in most of the 16 federal states of Germany. In 2009, a collaborative project involving cancer registries and the German Cancer Research Centre (DKFZ) has been initiated, which now offers the possibility to study recent data from 11 German population-based cancer registries, covering 33 million inhabitants (Hiripi et al, 2011). The aim of this study is to

\footnotetext{
*Correspondence: Dr H Brenner; E-mail: h.brenner@dkfz.de

${ }^{8}$ Members of the working group are listed in the Acknowledgements Received 23 January 2012; revised 3 April 2012; accepted 7 April 2012; published online 3 May 2012
}

describe colorectal cancer survival over the period 2002-2006 stratified by sex, age, detailed subsites of left and right colon and rectum, morphology and disease extent. Moreover, our objective is to describe recent survival trends using the technique of modelbased period analysis.

\section{MATERIALS AND METHODS}

\section{Sources of data}

German cancer registries covering 13 of 16 federal states and 1 administrative region submitted data for the study. Only cancer registries with estimated completeness over $80 \%$ in the period 2004-2006 and reasonably low proportion of death certificate only (DCO) cases (under 20\% throughout the study period or constantly decreasing to levels $<20 \%$ at the end of study period) were considered for the analysis. We eventually utilised data from 11 cancer registries covering a population of 33 million inhabitants. Full details were described in detail elsewhere (Hiripi et al, 2011).

We selected patients with a primary invasive colorectal cancer (ICD-10 C18-C20) at the age of $\geqslant 15$ years in 1997-2006. We excluded cases notified by DCO. For the stage-specific analysis, 
stage grouping according to ENCR recommendations (localised, regional and advanced cancer) was used (Berrino et al, 2002).

Site and morphology of tumours were coded according to ICD-O-3 (Fritz, 2000). When aggregated subsites were used, right colon included caecum (C18.0), ascending colon (C18.2), hepatic flexure (C18.3) and transverse colon (C18.4). Left colon included splenic flexure (C18.5), descending (C18.6) and sigmoid (C18.7) colon. We used five morphology groups (invasive behaviour only): adenocarcinoma in polyp $(8210,8261,8263)$, mucinous adenocarcinoma $(8470,8480,8481,8490)$, other adenocarcinoma (8140-47, 8190-8221, 8260-8323, 8380-8550, 8570, 8940) and others.

\section{Statistical methods}

To quantify excess mortality due to cancer, relative survival is commonly used in population-based studies. It is derived as the ratio of the observed survival of cancer patients and the expected survival of the underlying general population (Henson and Ries, 1995). In our analysis, expected survival was estimated by the Ederer II method using life tables stratified by age, sex, calendar period and federal state as obtained from participating cancer registries and the German Federal Statistical Office. To allow for comparisons between subgroups or populations with potentially different age distribution, age adjustment was done using the International Cancer Survival Standards proposed by Corazziari et al (2004).

Period analysis (Brenner et al, 2004) was employed to provide up-to-date estimates of 5-year survival in 2002-2006. Extensive empirical evaluations have shown that period analysis provides 5 -year survival estimates that are very close to 5-year survival later observed for the patients diagnosed within the period of investigation (Brenner and Hakulinen, 2002; Brenner et al, 2002b). In addition, model-based period analysis (Brenner and Hakulinen, 2006) was used to investigate recent trends and to perform statistical testing. Briefly, excess numbers of deaths were modelled as a function of calendar year (numerical variable), and year of follow-up (categorical variable) in Poisson regression models, with the logarithm of the person-years at risk as an offset. Individual models were fitted for different groups of patients by age, clinical stage or disease localisation to estimate magnitude and significance of time trends. Moreover, models including year of follow-up and sex (both categorical variables) were fitted for subgroups by age to test for gender differences.

All calculations were carried out by SAS 9.2 software (SAS Institute, Cary, NC, USA), using a publicly available macro for period analysis (Brenner et al, 2002a) and its adaptation for modelbased period analysis (Brenner and Hakulinen, 2006).

\section{RESULTS}

The analysis was based on records of 164996 colorectal cancer patients from 11 German cancer registries. Slightly more than half of the patients were males (52.5\%, ranging from 46.6 to $56.2 \%$ across registries). Median age was 70 years (range 68-72). More than $94 \%$ of cases were microscopically confirmed in every registry (Table 1).

Table 2 shows sex differences and time trends in survival by age groups. Age-adjusted 5-year relative survival was higher in women by $2.6 \%$ units. Significantly higher survival in women compared with men was observed in patients under 75 years of age; however,

Table I Description of the data set used in period survival analysis, colorectal cancer patients diagnosed in 1997-2006 in Germany

\begin{tabular}{lcccccc}
\hline Registry & $\begin{array}{c}\text { Diagnosis period } \\
\text { included }\end{array}$ & Cases & $\begin{array}{c}\text { Exclusion based on } \\
\text { DCO or autopsy (\%) }\end{array}$ & $\begin{array}{c}\text { Available } \\
\text { cases }\end{array}$ & $\begin{array}{c}\text { Males (\%) } \\
\text { Micr }\end{array}$ & $\begin{array}{c}\text { Median age } \\
\text { at diagnosis }\end{array}$ \\
confirmed (\%)
\end{tabular}

Table 2 Age-specific 5-year relative survival (RS) of colorectal cancer for the period 2002-2006 by sex and modelled trends in age-specific survival

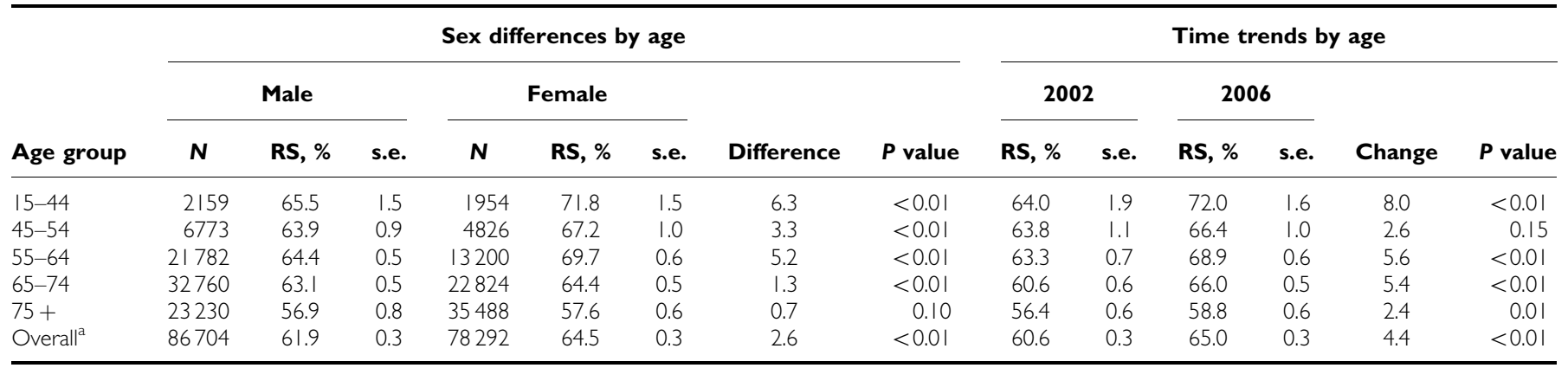

${ }^{a}$ Age-adjusted relative survival, testing performed using age-adjusted model. 
Table 3 Age-adjusted 5-year relative survival (RS) of colorectal cancer in subsites for the period 2002-2006 by morphology

\begin{tabular}{|c|c|c|c|c|c|c|c|c|c|c|}
\hline \multirow[b]{2}{*}{ Subsite } & \multicolumn{2}{|c|}{ Overall } & \multicolumn{2}{|c|}{$\begin{array}{l}\text { Adenocarcinoma } \\
\text { in polyp }\end{array}$} & \multicolumn{2}{|c|}{$\begin{array}{c}\text { Mucinous } \\
\text { adenocarcinoma }\end{array}$} & \multicolumn{2}{|c|}{$\begin{array}{c}\text { Other } \\
\text { adenocarcinoma }\end{array}$} & \multicolumn{2}{|c|}{ Other } \\
\hline & $N$ & RS (s.e.) & $N(\%)$ & RS (s.e.) & $N(\%)$ & RS (s.e.) & $N(\%)$ & RS (s.e.) & $N(\%)$ & RS (s.e.) \\
\hline Overall & 164996 & $63.0(0.2)$ & $759 \mid(4.6)$ & $78.0(1.0)$ & $16922(10.3)$ & $59.5(0.7)$ & $129127(78.3)$ & $64.3(0.2)$ & II 356 (6.9) & $38.9(0.7)$ \\
\hline ppendix & 1103 & $66.4(2.9)$ & $15(1.4)$ & & $297(26.9)$ & & $342(31.0)$ & & $449(40.7)$ & \\
\hline $\begin{array}{l}\text { Caecum } \\
\text { Ascending colon } \\
\text { Hepatic flexure } \\
\text { Transverse colon } \\
\text { Right colon }\end{array}$ & $\begin{array}{r}14604 \\
16087 \\
5043 \\
7880 \\
43614\end{array}$ & $\begin{array}{l}61.7(0.8) \\
66.5(0.7) \\
61.2(1.3) \\
63.5(1.0) \\
63.8(0.4)\end{array}$ & $\begin{array}{r}615(4.2) \\
539(3.4) \\
135(2.7) \\
264(3.4) \\
1553(3.6)\end{array}$ & $\begin{array}{l}76.6(4.1) \\
77.5(3.8)\end{array}$ & $\begin{array}{r}2340(16.0) \\
2365(14.7) \\
675(13.4) \\
1072(13.6) \\
6452(14.8)\end{array}$ & $\begin{array}{l}59.3(1.9) \\
66.4(1.8) \\
66.7(3.5) \\
61.4(2.6) \\
63.0(1.1)\end{array}$ & $\begin{array}{r}10726(73.4) \\
12399(77.1) \\
3981(78.9) \\
6141(77.9) \\
33247(76.2)\end{array}$ & $\begin{array}{l}62.5(0.9) \\
67.7(0.8) \\
61.7(1.4) \\
64.8(1.1) \\
64.8(0.5)\end{array}$ & $\begin{array}{r}923(6.3) \\
784(4.9) \\
252(5.0) \\
403(5.1) \\
2362(5.4)\end{array}$ & $\begin{array}{l}43.8(2.6) \\
34.4(3.2) \\
22.8(4.7) \\
37.0(4.4) \\
38.6(1.8)\end{array}$ \\
\hline $\begin{array}{l}\text { Splenic flexure } \\
\text { Descending colon } \\
\text { Sigmoid colon } \\
\text { Left colon }\end{array}$ & $\begin{array}{r}3630 \\
5135 \\
38331 \\
47096\end{array}$ & $\begin{array}{l}60.3(1.5) \\
67.7(1.2) \\
65.3(0.5) \\
65.2(0.4)\end{array}$ & $\begin{array}{r}112(3.1) \\
241(4.7) \\
2083(5.4) \\
2436(5.2)\end{array}$ & $\begin{array}{l}85.5(1.7) \\
83.9(1.6)\end{array}$ & $\begin{aligned} & 425(11.7) \\
& 544(10.6) \\
& 3047(7.9) \\
& 4016(8.5)\end{aligned}$ & $\begin{array}{l}63.5(4.1) \\
62.2(3.7) \\
57.9(1.6) \\
58.9(1.4)\end{array}$ & $\begin{array}{r}2917(80.4) \\
4142(80.7) \\
31370(81.8) \\
38429(81.6)\end{array}$ & $\begin{array}{l}61.2(1.6) \\
69.1(1.4) \\
66.1(0.5) \\
66.0(0.5)\end{array}$ & $\begin{array}{r}176(4.8) \\
208(4.1) \\
1831(4.8) \\
2215(4.7)\end{array}$ & $\begin{array}{l}37.9(2.0) \\
36.9(1.8)\end{array}$ \\
\hline $\begin{array}{l}\text { Rectosigmoid } \\
\text { Rectum } \\
\text { Rectum and rectosigmoid }\end{array}$ & $\begin{array}{r}7252 \\
53129 \\
60381\end{array}$ & $\begin{array}{l}65.2(1.1) \\
60.7(0.4) \\
61.2(0.4)\end{array}$ & $\begin{array}{r}365(5.0) \\
2670(5.0) \\
3035(5.0)\end{array}$ & $\begin{array}{l}73.9(1.8) \\
74.1(1.7)\end{array}$ & $\begin{array}{r}693(9.6) \\
4136(7.8) \\
4829(8.0)\end{array}$ & $\begin{array}{l}59.6(3.4) \\
53.8(1.3) \\
54.7(1.3)\end{array}$ & $\begin{array}{r}5885(81.2) \\
42854(80.7) \\
48739(80.7)\end{array}$ & $\begin{array}{l}66.7(1.2) \\
61.8(0.4) \\
62.3(0.4)\end{array}$ & $\begin{array}{r}309(4.3) \\
3469(6.5) \\
3778(6.3)\end{array}$ & $\begin{array}{l}35.9(4.2) \\
41.9(1.3) \\
41.4(1.3)\end{array}$ \\
\hline
\end{tabular}

Abbreviation: NOS = not otherwise specified. Unstable estimates of survival (s.e. $\geqslant 5 \%$ or $N<100$ or missing age-specific estimate) were omitted. All percentages represent proportions of row totals. The 'Other' group also included microscopically unverified cases.

the difference was smaller in individuals over 65. Model-based period analysis indicated an increase in age-adjusted 5-year relative survival from 60.6 to $65.0 \%$ over the period $2002-2006$. Survival significantly increased in all age groups except patients aged $45-54$ years.

Table 3 shows the distribution of patients and differences in ageadjusted survival in subgroups by subsite and morphology. Most patients $(\sim 80 \%)$ were diagnosed with cancer of the morphological group 'Other adenocarcinoma'. Adenocarcinomas in polyp were more often diagnosed in the left colon and rectum than in the right colon, whereas mucinous carcinomas were more prevalent in proximal sites $(14.8 \%$ in right colon $v s 8.5 \%$ in left colon and $7.8 \%$ in rectum).

Overall age-adjusted 5-year relative survival of $63.0 \%$ was observed for colorectal cancer patients. Survival was higher in colon cancer patients $(63.8 \%)$ than in rectal cancer patients $(60.7 \%)$. Localisation of the disease in left colon was associated with a slightly higher survival $(65.2 \%)$ in comparison with right colon $(63.8 \%)$. When looking at detailed colonic subsites irrespective of the laterality, highest survival was observed in patients with cancer in descending $(67.7 \%)$ and ascending $(66.5 \%)$ colon and appendix (66.4\%). Cancers in caecum $(61.7 \%)$, hepatic $(61.2 \%)$ and splenic $(60.3 \%)$ flexures were associated with somewhat lower survival. Survival was $<60 \%$ in patients with cancer within unspecified or overlapping site.

Overall 5-year relative survival was substantially higher for adenocarcinomas in polyp $(78.0 \%)$, which had the best prognosis in all subsites. Patients with mucinous adenocarcinomas had similar survival as the overall group when the cancer was located in the right colon, but prognosis was substantially worse when the mucinous carcinoma was located in the left colon or rectum. For adenocarcinoma in polyp, mucinous adenocarcinoma and other adenocarcinoma, survival was always worse for rectal cancer patients than for those with colon cancer. Prognosis of patients with cancer of other/unrecorded morphological types was poor in both colon $(37.4 \%)$ and rectum $(41.4 \%)$.

Table 4 shows distribution of clinical stages in different subsites and respective estimates of 5 -year relative survival. Stage was reported for $95422(57.8 \%)$ cancer patients, of whom $44.2 \%, 27.7 \%$ and $28.1 \%$ were diagnosed in localised, regional and advanced stage, respectively. Proportion of cases with known stage was similar over all subsites (range 56-64\%), exceptions are appendix $(47 \%)$ and colon, NOS (35\%). There was a very large gradient in prognosis by stage of disease, with overall age-adjusted 5-year relative survival of $89.5 \%, 65.4 \%$ and $14.9 \%$ for patients with localised, regional and advanced tumour spread, respectively. For every clinical stage, survival was higher in colon cancer patients than in rectal cancer patients. The survival was slightly higher in left colon cancer patients compared with right colon cancer patients with regional $(69.0 \%$ vs $66.0 \%)$ or advanced disease $(16.5 \%$ vs $13.7 \%)$. The lowest proportion of localised disease within individual colonic segments was reported in patients with cancer in caecum $(41.5 \%)$ and splenic flexure (42.2\%), the highest in descending colon $(47.3 \%)$. The lowest proportion of advanced disease was reported in patients with cancer in ascending (26.4\%) and descending colon (26.8\%).

Table 5 provides estimates of recent trends in survival according to site and clinical stage. Significant increase in overall 5-year relative survival was noted in both colon and rectal cancer patients (by $4.6 \%$ and $4.0 \%$ units, respectively). Most pronounced increase in stage-specific survival was noted in patients with regional disease (significant increase by $4.3 \%$ and $6.0 \%$ units for colon and rectal cancer patients, respectively). A less pronounced increase was noted for patients with localised disease (not significant for rectal cancer patients). No significant changes in survival were observed for patients with metastatic colorectal cancer.

\section{DISCUSSION}

This study provides estimates of colorectal cancer survival of German patients over the period 2002-2006, based on a population of 33 million people. Overall 5-year relative survival was $63 \%$, and a significant increase by $>4 \%$ units was seen even within this relatively short period of time. A higher 5-year relative survival was noted in younger males and females. Survival in women was significantly higher than for males $<75$ years of age. Prognosis of 
Table 4 Age-adjusted 5-year relative survival (RS) of colorectal cancer in subsites by stage for the period 2002-2006

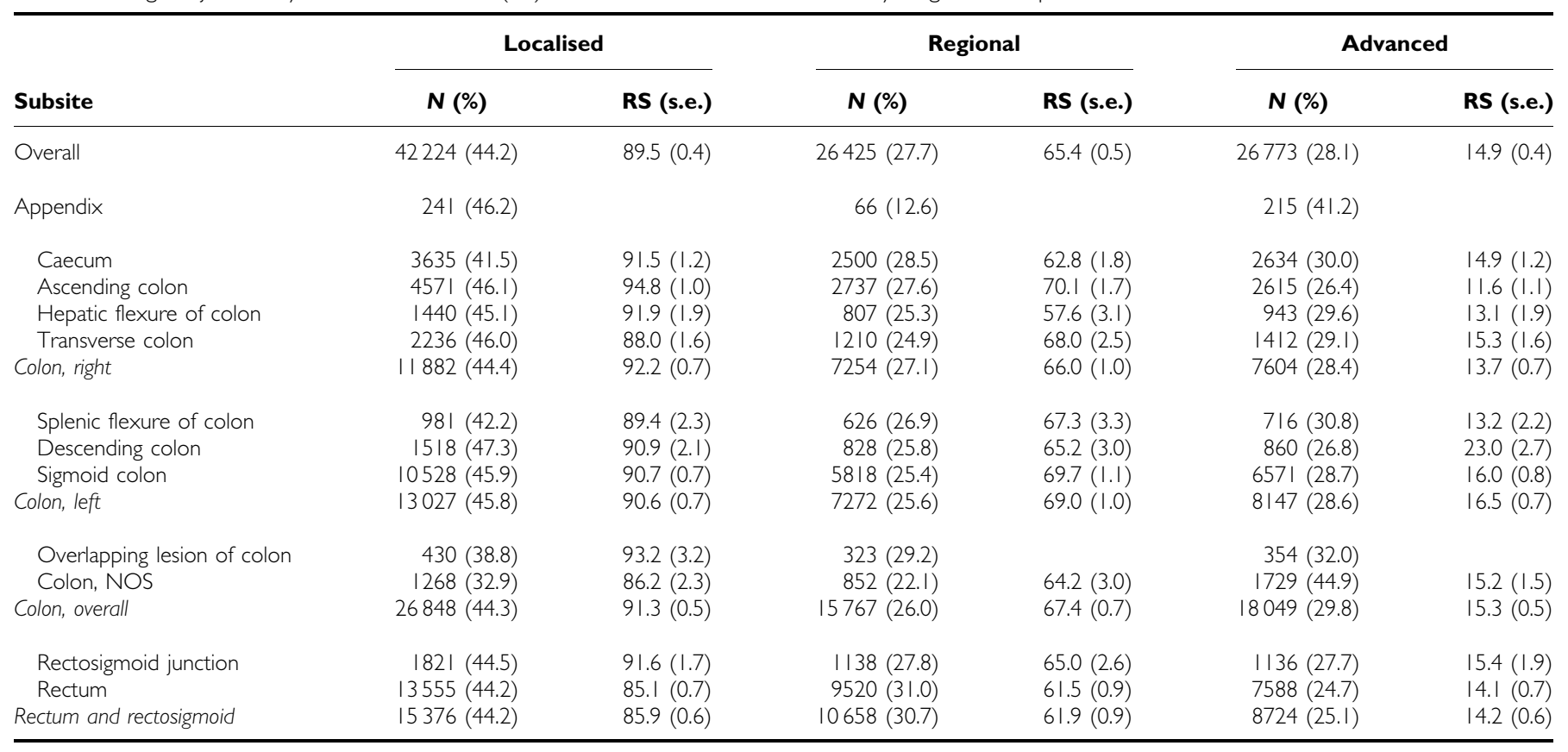

Abbreviation: NOS = not otherwise specified. Unstable estimates of survival (s.e. $\geqslant 5 \%$ or $\mathrm{N}<100$ or missing age-specific estimate) were omitted. All percentages represent proportions of row totals (percentage among cases with known stage).

Table 5 Recent trends in age-adjusted 5-year relative survival (RS) by site and stage according to model-based period analysis, 2002-2006

\begin{tabular}{|c|c|c|c|c|c|c|c|}
\hline \multirow[b]{2}{*}{ Site } & \multirow[b]{2}{*}{ Stage } & \multicolumn{2}{|c|}{2002} & \multicolumn{2}{|c|}{2006} & \multirow{2}{*}{$\begin{array}{c}\text { Change } \\
2002-2006\end{array}$} & \multirow[b]{2}{*}{$P$ value } \\
\hline & & RS, \% & s.e. & RS, \% & s.e. & & \\
\hline All & $\begin{array}{l}\text { Localised } \\
\text { Regional } \\
\text { Advanced } \\
\text { Overall }\end{array}$ & $\begin{array}{l}87.9 \\
62.5 \\
15.1 \\
60.6\end{array}$ & $\begin{array}{l}0.6 \\
0.9 \\
0.5 \\
0.3\end{array}$ & $\begin{array}{l}90.6 \\
67.6 \\
15.7 \\
65.0\end{array}$ & $\begin{array}{l}0.5 \\
0.8 \\
0.5 \\
0.3\end{array}$ & $\begin{array}{l}2.8 \\
5.1 \\
0.5 \\
4.4\end{array}$ & $\begin{array}{c}<0.01 \\
<0.01 \\
0.71 \\
<0.01\end{array}$ \\
\hline Colon & $\begin{array}{l}\text { Localised } \\
\text { Regional } \\
\text { Advanced } \\
\text { Overall }\end{array}$ & $\begin{array}{l}89.1 \\
65.0 \\
15.2 \\
61.4\end{array}$ & $\begin{array}{l}0.9 \\
1.1 \\
0.6 \\
0.4\end{array}$ & $\begin{array}{l}92.5 \\
69.3 \\
16.5 \\
66.0\end{array}$ & $\begin{array}{l}0.6 \\
1.0 \\
0.6 \\
0.4\end{array}$ & $\begin{array}{l}3.4 \\
4.3 \\
1.4 \\
4.6\end{array}$ & $\begin{array}{l}<0.01 \\
0.01 \\
0.13 \\
<0.01\end{array}$ \\
\hline $\begin{array}{l}\text { Rectum and } \\
\text { rectosigmoid }\end{array}$ & $\begin{array}{l}\text { Localised } \\
\text { Regional } \\
\text { Advanced } \\
\text { Overall }\end{array}$ & $\begin{array}{l}84.6 \\
58.5 \\
15.7 \\
59.0\end{array}$ & $\begin{array}{l}1.1 \\
1.4 \\
0.9 \\
0.6\end{array}$ & $\begin{array}{l}86.9 \\
64.5 \\
14.3 \\
63.1\end{array}$ & $\begin{array}{l}1.0 \\
1.3 \\
0.9 \\
0.5\end{array}$ & $\begin{array}{c}2.4 \\
6.0 \\
-1.4 \\
4.0\end{array}$ & $\begin{array}{c}0.08 \\
<0.01 \\
0.08 \\
<0.01\end{array}$ \\
\hline
\end{tabular}

Overall estimate includes cases without recorded information on clinical stage.

rectal cancer patients was worse than for colon cancer patients, where best prognosis was seen for tumours in ascending and descending colon. Patients with adenocarcinoma in polyp had the best survival expectations irrespective of the disease subsite. Very large differences in survival were seen between localised, regional and distant colorectal cancers. Recent increase in stage-specific survival was substantial for patients with localised cancer and especially those with regionally spread disease, whereas no increase was achieved for patients with metastatic disease.

Our overall estimate of 5-year relative survival of $63 \%$ for the 2002-2006 period is substantially higher than estimates previously reported for earlier periods from the majority of European countries including Germany (Verdecchia et al, 2007). Although previous estimates for Germany were restricted to Saarland, covering a population of only about $3 \%$ of the population included in the current study, a very similar result was obtained when we restricted our current analysis to Saarland, suggesting that the difference in survival is due to a further increase over time rather than to a regional variation. Our findings of decreasing survival with increasing age are consistent with observations from other European countries (Berrino et al, 2007). The existing gap between older and younger patients has been observed to be growing (Quaglia et al, 2009), which was also seen in our study, as survival increase in elder patients was weaker in comparison with young and middle-aged patients. Our observation of higher survival in female than in male patients, especially at younger ages, is likewise consistent with previous studies (Micheli et al, 2009). Hormonal factors have been suggested as a possible explanation for this observation (Koo et al, 2008).

We were able to provide relative survival estimates for cancer in different subsites of left and right colon. The overall estimate of 5 -year relative survival was only slightly higher for left colon cancer patients; however, this difference did not apply for all subsites of left and right colon. Survival of patients with tumours located in ascending colon was considerably higher compared with the rest of the right colon. On the other hand, splenic flexure tumours were associated with lower survival compared with adjacent segments and overall survival for left colon cancers. Few reports actually provided detailed description of survival across colonic subsites. One of the most comprehensive papers dealing with the importance of colon cancer subsites and morphology was a study comparing survival between EUROCARE and SEER by Gatta et al (2003). This study was, however, concerned primarily with explanation of international differences and did not focus on differences between subsite- and morphology-specific survival estimates. Moreover, published estimates were based on patients diagnosed in 1985-1989, and were therefore considerably lower than in our study.

Right-sided colon cancer patients are older, more likely to be women and are diagnosed with more advanced disease. Survival of right colon cancer patients is still lower, even after controlling for age, sex and stage using statistical modelling (Meguid et al, 2008; 
Wray et al, 2009; Benedix et al, 2010). This is usually explained by differences in tumours originating in right and left colon. These may include different carcinogenic pathways, difference in exposure to risk factors or differential sensitivity to chemotherapy (Iacopetta, 2002). However, several prognostic factors change across specific subsites irrespective of colon side, notably disease extent, as measured by TNM status or disease stage. A recent German study showed caecum and splenic flexure to have least favourable distribution of clinical stages. On the contrary, diseases originating in ascending and descending colon were diagnosed early (Benedix et al, 2011). Bearing in mind very large differences in colorectal cancer stage-specific survival, these findings may likely explain the results seen in our population-based study. Indeed, these findings are in line with distributions of clinical stages across colonic segments seen in our study.

Our study also estimated up-to-date survival of patients with colorectal cancer of different morphological properties. Adenocarcinoma in polyp had the best prognosis in all subsites. Mucinous adenocarcinoma has a less favourable prognosis in left colon and rectal cancer patients only.

Stage at diagnosis has been reported as an important explanation for observable survival differences between populations (Gatta et al, 2000; Ciccolallo et al, 2005), but it is often unavailable in population-based studies (Morris et al, 2011). Our study reported stage-specific relative survival estimates in colorectal subsites and showed substantial survival advantages of patients with early-stage tumours. Our results also suggest a higher survival of left-sided colon cancer patients with regional and metastatic disease. This is similar to previous results of studies using proportional hazards regression performed in the United States (Meguid et al, 2008; Wray et al, 2009).

Progress in survival can be attributed to either earlier detection (increasing proportion of early disease) or improvements in treatment (Brenner et al, 2007). The latter is observable as an increase in stage-specific survival. In our study, both overall survival and stage-specific survival in patients with localised or regional disease were increasing over the period 2002-2006. As the stage-specific survival increases in patients with colon cancer were weaker than the overall increase, a shift of stage distribution towards earlier stages at diagnosis may partially account for the observed increase in survival. Such a shift may be explained in part by the expansion of long standing screening offers with faecal occult blood test by the offer of screening colonoscopy in Germany in 2002 (Gross et al, 2006). This suggestion is supported by a particularly strong increase in survival between 55 and 74 years of age, where most of the screening takes place (Brenner et al, 2009b). Cancer screening may add lead time or overdiagnosis bias to survival estimates (Dickman and Adami, 2006); therefore, trends in incidence and mortality have to be monitored along with trends in survival to provide a comprehensive picture of colorectal cancer control. As both incidence and mortality are decreasing since the early 2000s in Germany (Husmann et al, 2010), it is unlikely that observed trends in population survival could be fully explained by screening-associated biases. Rather, the trends in incidence and mortality point to true reduction of the burden of colorectal cancer in Germany to which both early detection and treatment may have contributed.

Contrary to localised and regional disease, no significant improvement in prognosis was observed for metastatic colorectal cancer. Even though there has been marked improvement in recent trials, median survival of these patients has gradually improved from 6 months to 24 months only (Glimelius and Cavalli-Bjorkman, 2012), and the vast majority of these patients still die within 5-years after diagnosis. The persistent lack of progress in patients with distant tumour spread in our study and also in other European populations (Brenner et al, 2011) underlines the need of enhanced efforts of primary and secondary prevention.
Worse survival in certain colonic segments may be associated with less favourable distribution of clinical stages. Colonic segments with the highest proportion of localised and the lowest proportion of advanced cancers in our study (ascending and descending colon) were also harbouring tumours with highest 5 -year relative survival. The reasons for the unequal distribution of clinical stages in different colonic subsites may include worse endoscopic accessibility and visibility of certain colonic segments, notably colonic flexures and caecum (Bensen et al, 1999; Pickhardt et al, 2004; Benedix et al, 2011), which were also seen in our study to have both unfavourable stage distribution and lower survival. Efforts should therefore be made to ensure a high quality of colonoscopy, providing optimal visualisation of all parts of colon. This should be associated with an improved early detection or prevention of cancer in these problematic subsites (Rex et al, 2002).

Our study has a number of strengths and limitations. Major strengths of this study include the large number of patients and completeness of information on subsite and morphology. In particular, this collaborative study provides up-to-date survival estimates for Germany, which are based on an $\sim 30$-fold larger database than previously available population-based colorectal cancer survival data from Germany. The size of the database enabled very detailed survival analyses by age, sex, morphological subgroups and subsites. Major limitations include the still rather substantial exclusions of patients notified by DCO and the limited information on key prognostic variables, in particular stage at diagnosis. Although high proportions of DCO cases are partly due to the fact that many of the cancer registries are still rather young, and some proportion of DCO cases may simply be cases who had not been known to the registries as their diagnosis was made before the registration period, the relatively high DCO may be indicative of less than complete registration. As completeness of registration is typically lower for patients with poor prognosis, this may have led to some overestimation of survival (Pollock and Vickers, 1994).

Our analysis employing techniques of period survival analysis using large German national dataset provided up-to-date estimates of 5-year relative survival expectations for subgroups of patients according to sex and age suffering from cancers of different localisation, morphology and extent, showing substantial survival heterogeneity between certain groups. Model-based period analysis disclosed notable increase in survival over recent years, probably attributable to progress in care for patients with localised and regional colorectal cancer and earlier detection, which was also suggested by examination of age-specific trends.

\section{ACKNOWLEDGEMENTS}

This study was supported by the German Cancer Aid (Deutsche Krebshilfe) Grant no. 108257. The internship of OM at DKFZ was financially supported by the Czech Science Foundation - GACR (project no. 102/09/H083, Information Technology in Biomedical Engineering).

Members of the GEKID Cancer Survival Working Group: Karla Geiss, Martin Meyer (Cancer Registry of Bavaria), Andrea Eberle, Sabine Luttmann (Cancer Registry of Bremen), Roland Stabenow (Cancer Registry of Berlin and the New Federal States), Stefan Hentschel, Alice Nennecke (Hamburg Cancer Registry), Joachim Kieschke, Eunice Sirri (Cancer Registry of Lower Saxony), Bernd Holleczek (Saarland Cancer Registry), Katharina Emrich (Cancer Registry of Rhineland-Palatinate), Hiltraud Kajüter, Volkmar Mattauch (Cancer Registry of North Rhine-Westphalia), Alexander Katalinic (Cancer Registry of Schleswig-Holstein), Klaus Kraywinkel (Robert Koch Institute, Berlin), Hermann Brenner, Adam Gondos, Lina Jansen (German Cancer Research Center). 


\section{REFERENCES}

Benedix F, Kube R, Meyer F, Schmidt U, Gastinger I, Lippert H (2010) Comparison of 17,641 patients with right- and left-sided colon cancer: differences in epidemiology, perioperative course, histology, and survival. Dis Colon Rectum 53: 57-64

Benedix F, Schmidt U, Mroczkowski P, Gastinger I, Lippert H, Kube R (2011) Colon carcinoma-classification into right and left sided cancer or according to colonic subsite?-Analysis of 29,568 patients. Eur J Surg Oncol 37: 134-139

Bensen S, Mott LA, Dain B, Rothstein R, Baron J (1999) The colonoscopic miss rate and true one-year recurrence of colorectal neoplastic polyps. Polyp Prevention Study Group. Am J Gastroenterol 94: 194-199

Berrino F, Brown C, Moller T, Sobin L, Faivre J (2002) ENCR Recommendations-Condensed TNM for Coding the Extent of Disease. European Network of Cancer Registries. Available from http://www.encr. com.fr/extentofdisease.pdf (Accessed 17 October 2011)

Berrino F, De Angelis R, Sant M, Rosso S, Bielska-Lasota M, Coebergh JW, Santaquilani M (2007) Survival for eight major cancers and all cancers combined for European adults diagnosed in 1995-99: results of the EUROCARE-4 study. Lancet Oncol 8: 773-783

Brenner H, Bouvier AM, Foschi R, Hackl M, Larsen IK, Lemmens V, Mangone L, Francisci S, The Eurocare Working Group (2011) Progress in colorectal cancer survival in Europe from the late 1980s to the early 21st century: The EUROCARE study. Int $J$ Cancer; e-pub ahead of print 3 August 2011; doi:10.1002/ijc.26192

Brenner H, Francisci S, de Angelis R, Marcos-Gragera R, Verdecchia A, Gatta G, Allemani C, Ciccolallo L, Coleman M, Sant M (2009a) Long-term survival expectations of cancer patients in Europe in 2000-2002. Eur J Cancer 45: 1028-1041

Brenner H, Gefeller O, Hakulinen T (2002a) A computer program for period analysis of cancer patient survival. Eur $J$ Cancer 38: 690-695

Brenner H, Gefeller O, Hakulinen T (2004) Period analysis for 'up-to-date' cancer survival data: theory, empirical evaluation, computational realisation and applications. Eur J Cancer 40: 326-335

Brenner H, Gondos A, Arndt V (2007) Recent major progress in long-term cancer patient survival disclosed by modeled period analysis. J Clin Oncol 25: 3274-3280

Brenner H, Hakulinen T (2002) Up-to-date long-term survival curves of patients with cancer by period analysis. J Clin Oncol 20: 826-832

Brenner $\mathrm{H}$, Hakulinen $\mathrm{T}$ (2006) Up-to-date and precise estimates of cancer patient survival: model-based period analysis. Am J Epidemiol 164: 689-696

Brenner H, Hoffmeister M, Brenner G, Altenhofen L, Haug U (2009b) Expected reduction of colorectal cancer incidence within 8 years after introduction of the German screening colonoscopy programme: estimates based on 1,875,708 screening colonoscopies. Eur J Cancer 45: 2027-2033

Brenner H, Soderman B, Hakulinen T (2002b) Use of period analysis for providing more up-to-date estimates of long-term survival rates: empirical evaluation among 370,000 cancer patients in Finland. Int $J$ Epidemiol 31: 456-462

Ciccolallo L, Capocaccia R, Coleman MP, Berrino F, Coebergh JW, Damhuis RA, Faivre J, Martinez-Garcia C, Moller H, Ponz de Leon M, Launoy G, Raverdy N, Williams EM, Gatta G (2005) Survival differences between European and US patients with colorectal cancer: role of stage at diagnosis and surgery. Gut 54: 268-273

Coleman MP, Quaresma M, Berrino F, Lutz JM, De Angelis R, Capocaccia R, Baili P, Rachet B, Gatta G, Hakulinen T, Micheli A, Sant M, Weir HK, Elwood JM, Tsukuma H, Koifman S, GA ES, Francisci S, Santaquilani M, Verdecchia A, Storm HH, Young JL (2008) Cancer survival in five continents: a worldwide population-based study (CONCORD). Lancet Oncol 9: 730-756

Corazziari I, Quinn M, Capocaccia R (2004) Standard cancer patient population for age standardising survival ratios. Eur $J$ Cancer 40: 2307-2316

Dickman PW, Adami HO (2006) Interpreting trends in cancer patient survival. J Intern Med 260: 103-117

Fritz AG (2000) International Classification of Diseases for Oncology: ICD$O$, 3rd edn. World Health Organization: Geneva
Gatta G, Capocaccia R, Sant M, Bell CM, Coebergh JW, Damhuis RA, Faivre J, Martinez-Garcia C, Pawlega J, Ponz de Leon M, Pottier D, Raverdy N, Williams EM, Berrino F (2000) Understanding variations in survival for colorectal cancer in Europe: a EUROCARE high resolution study. Gut 47: 533-538

Gatta G, Ciccolallo L, Capocaccia R, Coleman MP, Hakulinen T, Moller H, Berrino F (2003) Differences in colorectal cancer survival between European and US populations: the importance of sub-site and morphology. Eur J Cancer 39: 2214-2222

GEKID (2011) GEKID-Atlas. Association of Population-based Cancer Registries in Germany (GEKID). Available from http://www.ekr.med. uni-erlangen.de/GEKID/Atlas/CurrentVersion/English/Inzidenz/atlas.html (Accessed 23 November 2011)

Glimelius B, Cavalli-Bjorkman N (2012) Metastatic colorectal cancer: current treatment and future options for improved survival. Medical approach-present status. Scand J Gastroenterol 47: 296-314

Gondos A, Bray F, Brewster DH, Coebergh JW, Hakulinen T, JanssenHeijnen ML, Kurtinaitis J, Brenner H (2008) Recent trends in cancer survival across Europe between 2000 and 2004: a model-based period analysis from 12 cancer registries. Eur J Cancer 44: 1463-1475

Gross CP, Andersen MS, Krumholz HM, McAvay GJ, Proctor D, Tinetti ME (2006) Relation between Medicare screening reimbursement and stage at diagnosis for older patients with colon cancer. JAMA 296: 2815-2822

Henson DE, Ries LA (1995) The relative survival rate. Cancer 76: 1687-1688

Hiripi E, Gondos A, Emrich K, Holleczek B, Katalinic A, Luttmann S, Sirri E, Brenner H (2011) Survival from common and rare cancers in Germany in the early 21st century. Ann Oncol; e-pub ahead of print 19 May 2011; doi:10.1093/annonc/mdr131

Husmann G, Kaatsch P, Katalinic A, Bertz J, Haberland J, Kraywinkel K, Wolf U (2010) Cancer in Germany 2005/2006. Incidence and Trends. Robert Koch-Institut: Berlin

Iacopetta B (2002) Are there two sides to colorectal cancer? Int J Cancer 101: 403-408

Koo JH, Jalaludin B, Wong SK, Kneebone A, Connor SJ, Leong RW (2008) Improved survival in young women with colorectal cancer. Am J Gastroenterol 103: 1488-1495

Meguid RA, Slidell MB, Wolfgang CL, Chang DC, Ahuja N (2008) Is there a difference in survival between right- versus left-sided colon cancers? Ann Surg Oncol 15: 2388-2394

Micheli A, Ciampichini R, Oberaigner W, Ciccolallo L, de Vries E, Izarzugaza I, Zambon P, Gatta G, De Angelis R (2009) The advantage of women in cancer survival: an analysis of EUROCARE-4 data. Eur J Cancer 45: 1017-1027

Morris EJ, Sandin F, Lambert PC, Bray F, Klint A, Linklater K, Robinson D, Pahlman L, Holmberg L, Moller H (2011) A population-based comparison of the survival of patients with colorectal cancer in England, Norway and Sweden between 1996 and 2004. Gut 60: 1087-1093

Pickhardt PJ, Nugent PA, Mysliwiec PA, Choi JR, Schindler WR (2004) Location of adenomas missed by optical colonoscopy. Ann Intern Med 141: 352-359

Pollock AM, Vickers N (1994) The impact on colorectal cancer survival of cases registered by 'death certificate only': implications for national survival rates. Br J Cancer 70: 1229-1231

Quaglia A, Tavilla A, Shack L, Brenner H, Janssen-Heijnen M, Allemani C, Colonna M, Grande E, Grosclaude P, Vercelli M (2009) The cancer survival gap between elderly and middle-aged patients in Europe is widening. Eur J Cancer 45: 1006-1016

Rex DK, Bond JH, Winawer S, Levin TR, Burt RW, Johnson DA, Kirk LM, Litlin S, Lieberman DA, Waye JD, Church J, Marshall JB, Riddell RH (2002) Quality in the technical performance of colonoscopy and the continuous quality improvement process for colonoscopy: recommendations of the U.S. Multi-Society Task Force on Colorectal Cancer. Am J Gastroenterol 97: 1296-1308

Verdecchia A, Francisci S, Brenner H, Gatta G, Micheli A, Mangone L, Kunkler I (2007) Recent cancer survival in Europe: a 2000-02 period analysis of EUROCARE-4 data. Lancet Oncol 8: 784-796

Wray CM, Ziogas A, Hinojosa MW, Le H, Stamos MJ, Zell JA (2009) Tumor subsite location within the colon is prognostic for survival after colon cancer diagnosis. Dis Colon Rectum 52: 1359-1366

This work is published under the standard license to publish agreement. After 12 months the work will become freely available and the license terms will switch to a Creative Commons Attribution-NonCommercial-Share Alike 3.0 Unported License. 